long run. They may make matters worse by deluding you that they obviate the need to put things right.

In the case of medicine I do not believe there is a public relations problem at all. Every doctor is his own best public relations expert. Your professional bodies stand high in the public esteem. Shaw's gibe may have been extreme, but it embodied a forced compliment.

What is wanted is a changed public attitude to medicine, an educated attitude.

At first glance, a seeming analogy is the Law. It affects us all. We are constantly aware of its hazards. We are perfectly entitled to cope with them ourselves. We hardly ever do so. We all have our ideas on one particular law or another, and on the Law's administration generally. We recognize none the less that it is a highly specialized job and happily leave it to the experts. Great pleaders, however unintentionally, attract immoderate publicity to themselves; the profession as a whole rides the burden comfortably. Lawyers dispute controversial issues in public with laymen cheerfully joining in ; no one, least of all the Law, seems to suffer in consequence.

Closer inspection, I think, shows the analogy is not a very good one. To begin with, the Law, by means of contempt of court and other sanctions, has ways of keeping the public in its place. Defiance of the Law brings immediate retribution; the consequences of flouting the laws of medicine are often so remote that to the very end the victim may never be conscious of them.

Again, although the legislators ring us round with more and more legal hazards, innumerable citizens, even motorists, do finish their lives without ever being in court. It is pretty well impossible in a civilized community to go from the cradle to the grave without recourse to a doctor at some stage or other. Conversely any citizen may become part of the Law as a juryman or a witness. None of us ordinary folk is likely to be asked to assist in an operation.

The penalties for spurning professional aid and being your own lawyer when in trouble present themselves much more sharply and direly than if you dose yourself with patent medicines or neglect to go to the doctor at all. Ignorance of the Law is said to be no valid excuse for any citizen ; ignorance (and, worse still, false ideas) about medicine are almost every man's lot.

(The one instance in which the analogy might be valid is that the Law undoubtedly gains from the fact that, for protective reasons, all big newspapers have lawyers on their staffs. This means that anything new or interesting in the legal world is bound to be brought to the editor's notice. If only it were as necessary to have medical men on the editorial staff, as well as on the personnel side, there would be more chance of medical news and opinion receiving proper attention.)

I used, a moment ago, the words "an educated attitude." Within the confined limits that are necessary for the happiness of the majority and the ordered running of society there is a partially educated attitude to the Law. It is by no means complete. But then, as I said earlier, the education of democracy is not yet complete in any respect. In the case of medicine it has hardly begun.

The truth is that the whole slow progress of men and women in free societies is a vast, continuous, unending experiment in education. Our western way of life will stand or fall on how broadly educated-I am using the word in no narrow technical sense-each nation can become. The problems of medical publicity may seem ridiculous against so great a background. They are in fact an essential part of it. All your fears and inhibitions spring from a lack of confidence in the public. That lack of confidence is due to the fact that by far the greater part of the public is medically uneducated. It is not educated even in a proper attitude towards its own ignorance.

The ancients wisely stressed the predominant place of health in human happiness. "A healthy mind in a healthy body" remains a universal ideal. Alas, it is an ideal not likely to be realized by mankind as a whole for centuries, or by this nation as a whole for generations. But if only we could all be taught to have healthy minds about unhealthy bodies that would be a big stride along the road. It might also mean that at the end of the road the doctors would have fared better than the gods, the priests, or the kings.

\section{IMPORTANCE OF FAILING VISION IN EARLY DIAGNOSIS OF SUPRASELLAR MENINGIOMAS}

\author{
BY \\ J. A. JANE, M.D. \\ Research Assistant, Atkinson Morley's Hospital. \\ London \\ AND \\ W. McKISSOCK, M.S., F.R.C.S. \\ Neurological Surgeon, St. George's Hospital and \\ National Hospital, Queen Square, London
}

The purpose of this paper is to draw attention to the desirability of the early diagnosis of intracranial tumours as a cause for failing vision, exemplified by a series of patients with suprasellar meningiomas. Cushing and Eisenhardt (1938), in describing their series of 28 suprasellar meningiomas, wrote: "Few meningiomas have a more distinctive symptomatology; few appear to have a better prognosis when surgically removed; and few promise in the future to be as easily recognized while still of small size." Progress towards the realization of the "promise in the future" has been slow indeed, as this paper shows.

\section{Present Series}

In a period of 25 years (1936-61) 858 proved cases of meningioma have been admitted under the care of one of us, of which 50 have originated in the suprasellar or intrasellar regions. A survey of these 50 cases shows that they can be roughly divided into two groups-those with tumours of very small size (17 cases) and those with tumours often of great extent (33 cases). The dividing line between the two groups was arbitrarily taken as a tumour greater or less than $3 \mathrm{~cm}$. in diameter, for above and below this size the technical problems of surgical removal are very different.

Broadly speaking, in the vast majority of cases the symptomatology in these 50 patients was confined to progressive failure of visual acuity and/or the appreciation by the patient of increasing limitation of the field 
of vision of one or both eyes. In only a few of the patients with "large" tumours was the onset of a different character, as is shown later. While there may be many causes of progressive loss of visual acuity and encroachment upon the visual fields, the possibility of early tumour should never be forgotten. In spite of the fact that these tumours originate in or close to the midline they often tend to affect one optic nerve more than the other and seldom produce an exact bitemporal hemianopia with equal diminution in acuity on the two sides. As Cushing and Eisenhardt state, "The field defects, while tending to be bitemporal, rarely progress with equal steps in the two eyes." There may, indeed, be progressive failure of acuity and a field defect of one eye alone.

Examination of the patients with such symptoms will usually reveal only a varying degree of pallor of one or both optic disks, diminution in visual acuity, and some form of field defect. Such symptoms and signs, alone, call for the fullest investigation.

Skull X-ray Films.-In most cases of early tumour there will be no change to be seen, although it is well known that these tumours later involve the underlying bone with the development of a visible hyperostosis. There may, however, be minimal changes in the anterior clinoid processes or enlargement of an optic foramen. Ordinary plain skull $x$-ray films may therefore be expected to be normal in the majority of cases with early small tumours.

Contrast $X$-ray Films.-Air introduced into the basal cisterns around the optic chiasm may show a small filling defect, and, similarly, air in the third ventricle may show distortion of the optic or infundibular recesses, either of these findings giving proof of the presence of a spaceoccupying lesion. Such abnormalities do not, however, indicate the pathology of the lesion. Angiography should always be resorted to in such cases, even when air studies have proved positive; for the compressing lesion may be, in fact, an aneurysm arising from the circle of Willis, the treatment for which might call for an entirely different surgical approach from that required for a suprasellar meningioma.

Treatment.-If the presence of a tumour has been proved by contrast radiography, then operation is indicated without delay: the small tumours can be removed with ease without worsening the visual acuity or field defect, without mortality, and with a reasonable prospect of an improvement in vision. On the contrary, if these ancillary examinations are negative and no other cause for the visual failure can be established, then exploratory operation should be undertaken. As Cushing and Eisenhardt say, "In the case of impaired vision with bitemporal field defects the safest rule is to look in and see what the cause may be without delay." We would amend this statement to include patients with progressive visual failure or field defect in a single eye.

\section{Case Material}

As the problems of large and small tumours are so different it will be sensible to review them separately. There were 33 patients ( 22 women, 11 men) with large tumours varying in size from $3 \mathrm{~cm}$. in diameter to enormous neoplasms filling most of both halves of the anterior cranial fossa and extending into the medial halves of each middle fossa. Their ages ranged from 31 to 71 years, with an average age of 49.8. Their histories varied between one month and eight years; with an average duration of 26.3 months. All but five showed some degree of impaired vision and/or field defect. Of these five, three complained of headaches, one of epilepsy, and the other of diplopia.

Straight $x$-ray films gave positive supportive evidence in 16 cases, but in all 33 either air studies or angiograms (if not both) indicated the presence of a space-occupying lesion.

In 16 cases total excision was achieved with seven deaths, and in 16 cases only partial removal was possible, again with seven deaths. One patient died before operation could be undertaken, having had a sudden haemorrhage from the tumour into the subarachnoid space and tumour substance. The operative mortality in this group of large tumours was thus 14 in 32 cases, or $42 \%$. The recurrence rate in the survivors after partial excision was $12 \%$. In only 8 of the 18 survivors was vision improved; in four it was worsened.

To return to the patients with small tumours, 14 of the 17 were females and 3 males, their ages ranging from 28 to 62 years and their histories of visual failure from five months to eight years. The average duration of symptoms was 36.4 months.

On examination all showed either blindness or diminished acuity, field defect, and optic atrophy in one or both eyes. None revealed any other abnormal neurological signs. Plain $x$-ray films of the skull were normal in all but four cases. Ventriculography and angiography showed nothing abnormal in three patients: in the remaining 14 one or other special radiological examination gave supportive evidence for the clinical diagnosis of compression of the optic nerve or chiasm by a space-occupying lesion.

At operation the tumours were found to vary in size from just under $3 \mathrm{~cm}$. in diameter to a frill of tumour only a few millimetres in thickness surrounding an optic nerve. In 10 of these cases complete macroscopic removal. was achieved, followed by coagulation of the dura mater at the point of origin of the growth. In seven total excision was not possible for technical reasons, and these seven were subsequently treated by irradiation. There was no operative death.

Subsequently eight cases were unchanged so far as visual acuity and field defect were concerned, but in nine there was definite and measurable improvement. In the 10 patients in whom complete excision of the tumour was achieved there has been no symptomatic or clinical evidence of recurrence over periods ranging up to 11 years since operation. In only two of the seven patients in whom subtotal removal was performed has there so far been clinical evidence of recurrence at 7 and 10 years after operation and deep $x$-ray therapy. The remaining five are still free from recurrence over periods varying from $2 \frac{1}{2}$ to 11 years.

The result of treating these 17 patients with early tumours has been to arrest the deterioration of vision in every case and to improve it in nine. In the two patients with recurrent tumours arrest of visual failure lasted for 7 to 10 years. No death has occurred.

A comparison of these two groups shows that whilst the larger tumours tended to be found in a rather older age-group (an average age of 49.8 years as opposed to 44 years), the average duration in symptoms was shorter in those with large tumours (26.3 months compared with 36.4 months). Women were more often affected than men, with a $4.6: 1$ preponderance in small and $2: 1$ in large tumours. 


\section{Discussion}

The great difference in results as regards the saving or improvement of vision as well as mortality is striking, but is easily explainable on anatomical grounds. When the tumour is of large size the anterior cerebral arteries, the anterior communicating vessel, and the distal anterior cerebral arteries are stretched tightly over its dome and posterior surface: the floor of the third ventricle is displaced far upwards and backwards, and the foramina of Munro may be occluded, resulting in dilatation of the lateral ventricles and greatly raised intracranial pressure. Damage to any of these structures is all too easily inflicted, with a possibly fatal outcome.

The optic nerves and chiasm are very extensively involved in these vast tumours, the nerves being greatly elongated and displaced backwards if not laterally as well, while the chiasm is broadened and thinned. and is pushed backwards and downwards. It is infinitely more difficult to free these structures from the tumours, for they are often adherent to the capsule, softer in consistency than normal, and very readily harmed during dissection. For this reason improvement in visual acuity or field is more difficult of achievement, while aggravation of pre-existing defects is all too common.

Operative intervention in early cases is a much simpier matter, especially with the aid of hypothermia and intravenous urea, which, by producing great shrinkage of the brain, enable the frontal lobe to be raised with ease and without trauma, providing an admirable view of all essential structures.

Unfortunately, early examination will not always reveal a small tumour, for the duration of symptoms was found to be actually less in the large tumours than in the small ones. This discrepancy can perhaps be explained by postulating the differing rates of growth of the tumours, but it is also possible that the exact point of origin of the growth is responsible in part. Once a tumour has reached a large size its area of dural attachment is extensive, and it can be imagined that some of them originated at a point well away from the actual optic foramina and sellar lip, thus allowing them considerable room for expansion before pressure on the nerves or chiasm becomes serious. The smaller, more strategically placed tumours in the immediate vicinity of the optic foramina would at once involve the appropriate optic nerve. Nevertheless, a slow rate of growth must be the answer in those patients with small tumours and a history of many months or years of visual disturbance. Although the suprasellar tumours are only a small group representing some $6 \%$ of meningiomas in this series (but nearly $9 \%$ in Cushing and Eisenhardt's) the establishment of the diagnosis at an early stage may well make the difference between life and death to the patient, to say nothing of the preservation, as opposed to the loss. of eyesight.

The average duration of two and a half and three and a half years of symptoms in these two series certainly leaves much to be desired in the direction of early diagnosis.

During this 25-year period when these 50 suprasellar meningiomas were encountered, 14 additional patients were subjected to exploration of the optic chiasm on the same clinical basis. In 5 of the 14 unmistakable chiasmal arachnoiditis was revealed, in one a glioma of the optic chiasm was found, and in the remainıng eight cases no abnormality of optic nerves or chiasm could be seen. No benefit accrued in any of these 14 cases as a result of exploration of the chiasm and nerves, although these structures were dissected free in the cases of arachnoiditis. The one patient with a chiasmal glioma could not be treated by excision of the tumour as this would have produced bilateral blindness. In none of these 14 patients was harm done by exploration.

It cannot be emphasized too strongly that progressive failure of vision, even in a single eye, justifies the earliest possible admission for specialized investigation. Only in this way can many tragedies be averted.

\section{Summary}

Fifty cases of suprasellar meningioma are reported, of which 17 were "small" and 33 "large."

The symptomatology was almost entirely confined to diminution in visual acuity and/or visual fields.

Surgical excision of the small tumours is attended by no mortality and there was a high proportion of improvement in visual signs and symptoms. Surgical excision of the large tumours is extremely difficult and has a high mortality rate.

Emphasis is laid upon the need for early diagnosis in the hope of being able to operate when these tumours are of small size.

Unfortunately length of history is no guide to the size of the tumour, and it is evident that there must be wide variations in their rates of growth.

\section{REFERE}

Cushing, H., and Eisenhardt, L. (1938). Meningiomas. Thomas, Springfield.

\section{VALUE OF NERVE-EXCITABILITY MEASUREMENTS IN PROGNOSIS OF FACIAL PALSY}

BY

\section{E. D. R. CAMPBELL, M.A., B.M., M.R.C.P.} D.Phys.Med

\section{R. P. HICKEY,* M.B., D.Phys.Med.}

K. H. NIXON, M.B., D.Phys.Med.

AND

\section{A. T. RICHARDSON, M.B., M.R.C.P., D.Phys.Med.}

\section{From the Department of Physical Medicine and} Rheumatology, Royal Free Hospital, London

Facial paralysis of lower-motor-neurone origin may be due either to physiological (reversible) block or to degeneration of the facial nerve. The prognosis depends on which has occurred, the chances of full recovery being good in physiological block but poor in degenera, tion. The present study demonstrates how accurately this knowledge may be acquired early in the course of the paralysis by a simple electrodiagnostic test.

\section{Historical Note}

Electrodiagnosis of facial palsies was first described by Duchenne (1872). He distinguished between motornerve-excitability tests and those based on local stimulation of individual muscles. For stimulation of the facial nerve as it leaves the stylomastoid foramen he recom-

*Now at St. Bartholomew's Hospital, Rochester, Kent. 